\title{
Treatment outcome indicators of schizophrenia according to Brazilian family caregivers and outpatients
}

Marcos Hirata Soares, Adriano Luiz da Costa Farinasso, Fernanda Pâmela Machado, Layla Karina Ferrari Ramos, Cristiane de Souza Gonçalves

Psychiatric and Mental Health Nursing, Department of Nursing, Universidade Estadual de Londrina, Brazil

Received: April 2, 2019

Accepted: May 26, 2019

Online Published: June 18, 2019

DOI: $10.5430 /$ jnep.v9n9p73

URL: https://doi.org/10.5430/jnep.v9n9p73

\begin{abstract}
Background and objective: The need to measure treatment outcomes in mental health services from the perspective of users and family members has been highlighted in the literature as a fundamental aspect to improve the care provided. The objective of this study was to measure the treatment outcome provided by a Brazilian Psychosocial Care Center from the perspective of outpatients and their family members.

Methods: A correlational study was performed with 84 outpatients and 40 family members, between 2015 and 2016, interviewing them using the Satisfaction (SATIS-BR), Perception of Change (PCS), Independent Living Skills (ILSS) and Family Burden (FBIS-BR) scales.

Results: There was a high index of satisfaction with the mental health service, with a mean of 4.23 for the users interviewed and 4.36 for the family members. The perception of change presented a mean of 2.58 for the patients and 2.19 for the family members. The independent living ability presented a mean of 2.52 .

Conclusions: The high indices of satisfaction suggest successes, as well as points to be improved in the mental health policy implemented in the municipality. However, reintegration into the labor market was presented as an aspect with a need for investments through health and labor policies, since it was related to the subjective burden.
\end{abstract}

Key Words: Mental health, Health policies, Research into health services

\section{INTRODUCTION}

The measurement of mental health outcomes is of great importance. In Canada, the experience with the evaluation of health care services is traditional. ${ }^{[1,2]}$ The use of indicators that take into account health determinants, the severity of diseases and the use of healthcare services would permit a better evaluation, implementing more standardized psychometric outcome measures. ${ }^{[2]}$

A review of mental health indicator development policies and practices was performed in Korea. ${ }^{[3]}$ Among the indicators, 10 were found to belong to the mental health system. The most important five mental health indicators are suicide rate, rate of increase in mental disorder treatment, burden caused by mental disorders, adequacy or identifying problems of mental health projects and deriving solutions and annual prevalence of mental disorders.

Mental health indicators currently in use in Brazil include suicide rates, psychiatric hospitalization rates, health resource

\footnotetext{
*Correspondence: Marcos Hirata Soares; Email: mhirata@uel.br; Address: Psychiatric and Mental Health Nursing, Department of Nursing, Universidade Estadual de Londrina, Brazil.
} 
utilization rates, community mental health care facilities, psychiatric beds per capita, etc. Unfortunately, these mental health indicators do not cover the broad spectrum of severity that characterizes this field. A literature review ${ }^{[4]}$ concluded that there are 3 indicators in all studies: structure (setting of care delivery), process (activities between provider and patient) and outcome (effectiveness and efficiency). In this study, outcome and process indicators were the most used.

The need to evaluate treatment outcomes in mental health services from the perspective of users and their family members has been highlighted in the literature, with it being necessary to develop further studies on this theme. ${ }^{[1-9]}$ In recent decades, studies on patient satisfaction regarding the treatment outcomes in mental health services have provided good feedback, since the changes perceived by the patients themselves can be considered to be one of the possible indicators of good outcomes due to the treatment received. ${ }^{[9]}$

Studies focusing on the evaluation of services ${ }^{[10]}$ have gained increasing relevance, given their importance in the patient care process. ${ }^{[11]}$ Furthermore, considering the family as part of the psychosocial treatment and rehabilitation process of the psychiatric patient is a fundamental part of the psychiatric care evaluation process. In Brazil, there are some studies on outcome quality indicators related to satisfaction from the perspective of users and relatives. In Rio Grande do Sul, ${ }^{[12]}$ two qualitative indicators of satisfaction were identified: less need for psychiatric hospitalization and the feeling of well being.

In São Paulo, a study ${ }^{[13]}$ presented and discussed a set of 16 indicators for the monitoring, evaluation and potential qualification of the Psychosocial Care Centers. The indicators were grouped into eight themes: care in a crisis situations; qualification of group meetings; networking; case management; continuing education; individualization of care; healthcare for people with intellectual disabilities; and the use of medication. The indicators were tested in services and are presented as a potentially useful tool to support the assessment, monitoring and management of Psychosocial Care Centers. The impact of the diagnosis of schizophrenia, the need to adapt to the new situation, the social stigma, the dependence and the implications of the chronicity of the clinical condition produce a burden on the family members, which, when identified, requires the service to perform interventions aimed at better adjustment to the treatment. ${ }^{[11-14]}$

Considering that the majority of studies are qualitative, standardized measures could provide scores that permit useful international comparisons. From a psychometric perspective, several studies ${ }^{[10,14]}$ have used instruments that measure a possible "degree" of psychosocial rehabilitation, measuring subjective constructs, such as independent living skills, that would indicate the perception of change due to the treatment provided and satisfaction with the service: measures correlated with psychosocial rehabilitation, under the psychometric theory approach that is configured as something measurable. ${ }^{[16]}$

The present study evaluated psychiatric care through possible indicators, which are not formalized as part of the Brazilian mental health policy, however, have been applied by researchers with broad experience in the area of mental health. The aim of this evaluation proposal is to assist in the planning and development of more specific interventions, as well as to evaluate their impact on the target population, thus contributing to the advancement of empirical and theoretical knowledge. ${ }^{[17]}$

\section{Method}

This cross-sectional and correlational study was conducted between January 2015 and August 2016, in a city in the state of Paraná, which has an Human Development Index (HDI) of $0.778^{[18]}$ and a population of approximately 485,822 inhabitants. The Psychosocial Care Network of the city is composed of Primary Health Care Facilities, Social Assistance Reference Centers, Street Clinics, Psychosocial Care Centers and psychiatric hospitalization beds.

\subsection{Participants}

A minimum sample of 132 cases, with an estimated loss of $10 \%$, a margin of error of 0.1 points and a value of $\alpha$ $=0.05$, was calculated using the IBM Sample Power v.3.0 program. The study included a sample of 84 outpatients with schizophrenia and 40 family caregivers verbally invited to be interviewed. The data were collected by nursing undergraduate students.

The inclusion criteria for the patients were the ability to properly understand the questions and to have been in treatment for at least 6 months. The inclusion criterion for the family members was for the interviewee to be the main family member who cared for the respective outpatient, with the exclusion criterion of the family member undergoing treatment for some mental disorder at the time.

\subsection{Instruments}

a) Patients' Satisfaction with Mental Health Services Scale (SATIS) ${ }^{[19]}$ Evaluates the satisfaction of users of mental health services. Factor or subscale 1: Degree of patient satisfaction regarding competence and understanding of the team with respect to their problem. Factor or subscale 2: Degree of patient satisfaction regarding the reception of the team and the help received in the service. Factor or subscale 
3: Degree of patient satisfaction regarding the physical conditions and comfort of the service.

b) Perception of Change Scale (PCS) Aims to evaluate the changes perceived by the patients themselves in various dimensions of their lives as a result of the treatment received in the mental health services, having been validated in Brazil. ${ }^{[20]}$

The Occupation and Physical Health subscale evaluates the changes perceived by the patients in the following aspects of their lives: leisure activities, energy, housework, ability to fulfill obligations and make decisions, interest in working or occupying themselves with something, appetite, sexuality and physical health. The Psychological Aspects and Sleep subscale evaluates changes in the aspects: feelings of selfconfidence, mood, personal problems, interest in life, ability to endure difficult situations and sleep. The third subscale, Relationships and Emotional Stability evaluates the coexistence with friends, family members and others in general and the stability of the emotions.

c) Independent Living Skills Survey (ILSS) This scale was adapted and validated for Brazil. ${ }^{[21]}$ It has 86 items that evaluate the autonomy of chronic patients in nine areas of daily life, in terms of the frequency with which they present the basic abilities to function independently in the community. These areas are: eating, personal care, domestic activities, food preparation and storage, health, leisure, money management, transportation and employment. The scores range from zero to four.

d) Family Burden Interview Scale (FIBS-BR) Adapted and validated for Brazil. ${ }^{[22]}$ The FBIS-BR scale evaluates both the objective and subjective burden of the family members. The objective burden is evaluated through the frequency in which the family member helps the patient in daily tasks (sub-scale A), has to deal with and supervise the patient's problematic behaviors (sub-scale B) and has undergone changes in his/her own professional and social life (sub-scale D) as a result of the caregiver role. This frequency is evaluated on a 5-point scale, where: $1=$ never, $2=$ less than once a week, $3=$ once or twice a week, $4=$ three to six times a week and $5=$ every day.

Subjective burden is assessed through the degree of discomfort felt by the family member when providing daily care to the patient (sub-scale A) and when dealing with problematic behaviors (sub-scale B), as well as through the family member's feeling of carrying a financial burden (one question of sub-scale C) and the frequency of concerns for the patient (sub-scale E). For the evaluation of the degree of discomfort, the response options are: $1=$ not at all, $2=$ very little, $3=$ a little and $4=$ a lot. For the assessment of concerns and financial burden, the response alternatives are: $1=$ never, 2
$=$ rarely, $3=$ sometimes, $4=$ often and $5=$ always or almost always.

\subsection{Data analysis}

The data were analyzed using the Statistical Package for the Social Sciences (SPSS), v.21. Firstly, the KolmogorovSmirnov test was performed to identify the normality of the distribution, with exploratory descriptive analysis, followed by Spearman's correlation test, since the data presented mainly non-normal distribution. To compare the means of the domains of the Perception of Change Scale, the $t$-test was used. The level of significance considered was $5 \%$.

\subsection{Ethical aspects}

The study was authorized by the Ethics Committee for Research with Human Subjects, under No. 18426114.7.0000.5231 and carried out according to the principles of research ethics. The study subjects were verbally invited to participate when they were in the service, with the terms of the study explained and the subjects that accepted signing the consent form.

\section{Results}

\subsection{Sociodemographic and clinical characterization}

The sample consisted of 84 patients attended in the CAPSIII and 40 family members. Regarding gender, the patient sample was composed of $50.0 \%$ women and $50.0 \%$ men, with $53.6 \%$ being single, $22.6 \%$ married, $6.0 \%$ divorced and $17.9 \%$ in other civil status categories. The age ranged from 18 to 69 years, mean (M) of 40.8 and standard deviation (SD) of 11.52 years. Regarding schooling, 57.0\% had elementary education, $42.0 \%$ had high school education and only $1 \%$ had higher education. Concerning income, $78.5 \%$ reported pensions, benefits and retirement as the main source of income, while $17.9 \%$ reported formal or informal employment as their main income and 3.6\% did not answer the question. The mean family income was $\mathrm{R} \$ 1,058.00$ ( $\mathrm{SD}=\mathrm{R} \$ 853.32$ ). The number of people in the family ranged from 1 to 12 people $(\mathrm{M}=3.3, \mathrm{SD}=2.11)$.

A total of $77.2 \%$ of the people had a diagnosis of some type of Schizophrenia and 22.8\% Bipolar Affective Disorder. The number of psychiatric hospitalizations ranged from 0 to $40(\mathrm{M}=5.3, \mathrm{SD}=8.5)$. Regarding the length of treatment, $26.7 \%$ were in treatment for 6 months, $9.3 \%$ for 7 to 12 months, $9.3 \%$ for 13 to 24 months, $18.7 \%$ for 25 to 60 months and $31 \%$ for 61 months or more, attending the service at least once a week.

In relation to the family members, the sample consisted of $60.0 \%$ women and $40.0 \%$ men, with ages ranging from 18 to 78 years $(\mathrm{M}=50, \mathrm{SD}=15.83)$. Regarding schooling, 
$55.0 \%$ had not completed elementary education, $40.0 \%$ had not completed high school and $2.5 \%$ had completed high school and not completed higher education. The number of people with whom the care was divided ranged from 0 to 17 people. Concerning the occupation, $40.0 \%$ mentioned a formal or informal job as their main source of income, $55.0 \%$ mentioned some type of benefit or retirement and $5.0 \%$ did not respond to the question, with the reported income ranging from $\mathrm{R} \$ 700.00$ to $\mathrm{R} \$ 6,000.00(\mathrm{M}=\mathrm{R} \$ 1,838.00, \mathrm{SD}=$ $\mathrm{R} \$ 1,195.15)$ (US\$170 to US\$1.500).

The results of the correlation analyses are presented in the following tables. However, due to space limitations, only domains with statistically significant data are presented. Correlations between domains of the same instrument were not highlighted.

Table 1 shows that for satisfaction with the service, the global mean represents $85.0 \%$ of the maximum score, considering that the SATIS score ranges from 1 to 5 .

Table 1. Mean scores (M) and standard deviation (SD) of Satisfaction with the service, of family members and patients of the Psychosocial Care Center, 2015-2016, Londrina, Paraná-Brazil

\begin{tabular}{ll}
\hline Scales/Domains & M (SD) \\
\hline Patients & $4.23(0.65)$ \\
Satisfaction with the Mental Health Service & $4.29(0.60)$ \\
Relationship with team & $4.10(0.68)$ \\
Conditions of the service and quality of the care & $4.30(0.67)$ \\
Appreciation of the service & $4.36(0.65)$ \\
Family Members & $4.50(0.68)$ \\
Satisfaction with the Mental Health Service & $4.40(0.65)$ \\
Treatment outcomes & $4.20(0.62)$ \\
Acceptance and Competence of the Team & Privacy and Confidentiality of the Team
\end{tabular}

According to Table 2, for the patients, the global mean represents $86.0 \%$ of the maximum score and for the relatives
$73.0 \%$, considering that the scale varies from 1 to 3 .

Table 2. Mean scores (M) and standard deviation (SD) of Perception of change, of family members and patients of the Psychosocial Care Center, 2015-2016, Londrina,

Paraná-Brazil

\begin{tabular}{ll}
\hline Domains/Samples & M (SD) \\
\hline Patients & $2.58(0.48)$ \\
Occupation & $2.54(0.53)$ \\
Psychological dimension & $2.62(0.50)$ \\
Interpersonal relationships & $2.66(0.50)$ \\
Physical health & $2.50(0.40)$ \\
Family Members & $2.19(0.52)$ \\
Occupation & $1.99(0.52)$ \\
Psychological dimension & $2.37(0.60)$ \\
Interpersonal relationships & $2.20(0.58)$ \\
Physical health & $2.21(0.38)$ \\
\hline
\end{tabular}

According to Table 3, there were statistically significant differences when comparing the mean scores of the scale domains applied with family members and outpatients. Greater differences can also be noticed between the domains of the PCS applied with the patients.

According to Table 4, the global mean represents $63.0 \%$ of the maximum score, since the score ranges from 0 to 4 . Considering the other tables, these were the lowest scores obtained in this population. Table 5 presents the correlation and determination coefficients between living skills and family burden.

According to Table 5, the highest correlation coefficient was found between the Employment domain and the level of discomfort of the family member in dealing with the problematic behavior of the patient $(-0.43 ; 18.5 \%$; $p<.001)$, that is, for only $18.5 \%$ of the cases, the variability of the data is explained in an inversely proportional way between these variables.

Table 3. Scores and $p$-value of the $t$-test for the PCS domains, of family members and Psychosocial Care Center outpatients, 2015-2016, Londrina, Paraná-Brazil

\begin{tabular}{lllll}
\hline Domains/Samples & Mean difference & $\mathbf{9 5 \% C I ~ l o w e r ~ l i m i t ~}$ & $\mathbf{9 5 \% C I ~ u p p e r ~ l i m i t ~}$ & Significance \\
\hline Family Members & & & \\
Occupation & 0.641 & 0.467 & 0.816 \\
Psychological dimension & 0.766 & 0.559 & 0.973 \\
Relationships & 0.709 & 0.517 & 0.902 & 0.902 \\
Physical health & 0.713 & 0.525 & & 0.001 \\
Patients & & & 1.943 & \\
Occupation & 1.717 & 1.492 & 2.013 & 1.603 \\
Psychological dimension & 1.782 & 1.551 & 1.914 & \\
Relationships & 1.422 & 1.240 & \\
Physical health & 1.697 & 1.480 &
\end{tabular}


Table 4. Mean scores (M) and standard deviation (SD) of Independent Living Skills of patients of the CAPS-III, 2015-2016, Londrina, Paraná-Brazil

\begin{tabular}{ll}
\hline Items & M (SD) \\
\hline Independent Living Skills & $2.52(0.90)$ \\
Eating & $2.81(0.77)$ \\
Personal care & $2.67(0.68)$ \\
Domestic activities & $3.07(1.06)$ \\
Food preparation and storage & $2.84(1.17)$ \\
Health & $2.60(0.84)$ \\
Money Management & $2.08(0.88)$ \\
Transport & $2.95(0.83)$ \\
Leisure & $2.02(0.82)$ \\
Employment & $1.71(1.05)$ \\
\hline
\end{tabular}

By correlating the domains of Perception of Change between family members and patients, a correlation was found in the Psychological domain $(0.37,13.7 \%, p<.05)$, between the Psychological domain, according to the patients and the Interpersonal Relationships domain, according to the family members $(0.34,11.6 \%, p<.05)$ and, finally, between the Occupation domain, according to the family members and the Relationships domain, according to the patients $(0.41$, $16.8 \% ; p<.05)$. When comparing the independent living skills with the Perception of Change in the family members, we found a correlation between the Psychological domain $(0.55,30.2 \%, p<.001)$ and the Physical Health domain $(0.43,18.5 \% ; p<.001)$, in the Employment domain. That is, for approximately $13.7 \%, 11.6 \%, 16.8 \%, 30.2 \%$ and $18.5 \%$, respectively, the variability of the data is explained by the binomial variables. These data suggest that there are other unexplained and unknown variables responsible for the variability of the data.

Table 5. Independent Living Skills (ILSS) of psychiatric patients and levels of Familial Burden (FBIS) of family members, 2015-2016, Londrina, Paraná-Brazil

\begin{tabular}{lllll}
\hline Burden of the Family Member & & & \\
\hline \multirow{2}{*}{$\begin{array}{l}\text { Domain/Spearman's } \\
\text { rho/CD/p }\end{array}$} & Objective & Subjective & \\
\cline { 2 - 5 } & $\begin{array}{l}\text { Problematic Behavior } \\
\text { Supervision }\end{array}$ & $\begin{array}{l}\text { Discomfort in providing } \\
\text { Help in the Daily Life }\end{array}$ & $\begin{array}{l}\text { Discomfort in dealing } \\
\text { with Problem Behavior }\end{array}$ & $\begin{array}{l}\text { Concerns with the } \\
\text { State of the Patient }\end{array}$ \\
\hline ILSS & & & & $-0.16(2.5 \%)$ \\
Personal Care & $-0.37(13.7 \%)$ & $-0.08(0.6 \%)$ & $-0.26(6.7 \%)$ & $(p>.05)$ \\
Money Management & $(p>.05)$ & $(p>.05)$ & $-0.22(4.8 \%)$ \\
Transport & $-0.20(4 \%)$ & $-0.33(10.9 \%)$ & $-0.32(10.2 \%)$ & $(p>.05)$ \\
& $(p>.05)$ & $(\boldsymbol{p}<.05)$ & $(\boldsymbol{p}<.05)$ & $-0.32(10.2 \%)$ \\
Leisure & $-0.13(1.7 \%)$ & $-0.39(15.2 \%)$ & $-0.40(16 \%)$ & $(p>.05)$ \\
& $(p>.05)$ & $(\boldsymbol{p}<.05)$ & $(\boldsymbol{p}<.05)$ & $-0.19(3.6 \%)$ \\
Employment & $0.06(0.3 \%)$ & $-0.22(4.8 \%)$ & $-0.33(10.9 \%)$ & $(p>.05)$ \\
& $(p>.05)$ & $(p>.05)$ & $(\boldsymbol{p}<.05)$ & $-0.41(16.8 \%)$ \\
\end{tabular}

\section{DISCUSSION}

In the present study, based on the sociodemographic profile data of the users, we verified the existence of information correlated with a study carried out in southern Brazil, ${ }^{[6,23]}$ in which the majority of respondents were in the age range from 40 to 59 years $(58.72 \%)$, with $80.95 \%$ being female. In addition, $39.00 \%$ of the interviewees were married at the time of the study; $58.73 \%$ had incomplete elementary education; $55.55 \%$ of them were retired and $59.79 \%$ lived with someone of the family.

Satisfaction and perception of change of the family members and patients The data collected through the present study show that the perception of satisfaction with the mental health service by the family members of the users was

Published by Sciedu Press satisfactory, since it presented a mean of 4.36, representing $87.0 \%$ of the maximum score. Regarding the perception of change by the family members, a mean of 2.19 was observed, equivalent to $73.0 \%$ of the maximum score.

A study conducted in Rio de Janeiro ${ }^{[24]}$ identified a mean overall satisfaction score of $3.9(\mathrm{SD}=0.6)$, indicating that, in general, the patients' family members were between "more or less satisfied" and "satisfied". In other studies conducted in Minas Gerais, ${ }^{[25]}$ Rio Branco ${ }^{[26]}$ and in southern Brazil, ${ }^{[27]}$ scores of 4.53, 4.24 and 4.37, respectively, were identified. Regarding the patients, scores of $4.15,4.61$ and 3.69 , respectively, were identified, suggesting that different regions present high satisfaction scores and that similar scores are likely to be found in other regions that have Psychosocial 
Care Center as the main system of treatment. Satisfaction with the service is also associated with other variables, as, according to a study using regression analysis, Perception of Change was classified as one of the main variables associated with satisfaction with the mental health service. ${ }^{[28]}$

According to Table 2, the perception of change presented lower scores than those measured by the patients, that is, the family member had a lower perception of improvement than the patient. Furthermore, there were statistically significant differences between the patient and family samples, which was also corroborated by another study carried out in some cities of Minas Gerais. ${ }^{[29]}$ Comparing a study performed in Pelotas-RS, ${ }^{[30]}$ the lowest scores were related to the Physical Health domain, as in the present study.

\subsection{Burden and independent living skills}

A study on the influence of the gender of the caregiver found that there are differences in subjective burden between men and women. In this study, ${ }^{[31]}$ the absence of children in the household and the number of people living in the household were considered to be predictors of greater subjective burden. The fact that parents are in direct contact, being the main caregivers, is corroborated in other studies, in which the parents are those most affected by the burden. ${ }^{[32,33]}$ Another variable associated with the burden of the caregiver is the degree of independence of the patient, which we evaluated in the present study. Independent living skills reflect, for the most part, greater success in psychosocial rehabilitation and may represent a greater or lesser degree of burden in the caregiver.

According to Table 4, the overall score measured by the ILSS scale was 2.52, the highest mean was in the Domestic Activities domain, with a score of 3.07 and the lowest, in the Employment domain, with 1.71. A recent study carried out in cities of Rio Grande do Sul, with 390 patients $^{[31]}$ accompanied by Therapeutic Residency Services (TRS), found a global score of 2.44, a score of 2.50 for Domestic Activities and a score of 1.00 for Employment. A study carried out in Barbacena, Minas Gerais ${ }^{[32]}$ with 75 TRS patients and another study with 584 patients from Porto Alegre, Rio Grande do Sul, hospitalized in a psychiatric hospital ${ }^{[28]}$ presented global scores of 2.29 and 1.13 , respectively. In the study with 75 patients, the score in the Eating domain was 3.85 , however, there was no evaluation of the Employment domain in these studies.

When comparing the data from the present study, we also noticed that the scores from different study sites and the numbers of subjects coming from community services were similar. Another study ${ }^{[26]}$ also identified that patients with schizophrenia presented low scores for life skills, being 0.54 for money management; 0.23 for transport; 0.47 for leisure; 0.98 for employment and 0.81 for maintenance of work.

Prejudice and the consequent lack of opportunity in the labor market are relevant factors that make it difficult for the social reintegration of people with mental disorders. A study of 2,475 mental disorder patients undergoing treatment in 15 Psychosocial Care Centers and 11 psychiatric hospitals ${ }^{[7]}$ that aimed to verify the association between mental illness and insertion in the labor market revealed that there is a greater chance of a temporary withdrawal from the job market for single, divorced or widowed women, those without stable housing and those hospitalized or first treated before the age of 18 years. The highest probability of definitive withdrawal from the labor market was observed among those of greater age. The temporary or definitive withdrawal was directly associated with low levels of schooling, the number of psychiatric hospitalizations and the presence of a severe mental disorder.

When the present study was correlated with a large study conducted in Rio Grande do Sul, ${ }^{[31]}$ we observed that the lowest scores obtained were in the Employment domain, also highlighting that the score presented in table 4 was $71 \%$ higher than that of the study cited; a fact that can be explained by the variety of cities involved in the study, compared to the single city of the present study. Table 5 confirms this hypothesis, as a negative correlation coefficient of 0.43 was obtained between Employment and Discomfort in Dealing with Problematic Behavior, that is, as well as in other domains evaluated in Table 5, an inversely proportional relationship was identified between domains of the degree of burden and certain domains of independent living skills.

\subsection{Final considerations}

The present study provides evidence that indicates that both the family members and the outpatients are satisfied with the quality of the mental health care provided, although a statistically significant difference was identified between the perception of change from the perspective of family members and outpatients. Although we did not evaluate limitations of the study, variables such as a single therapeutic project, types of medication used, among others, could justify the perception of improvement (or not) by the family, as well as evidence the development of the outpatients.

Both the outpatients and the family members interviewed showed that they felt satisfied with the service provided by the Psychosocial Care Center and the performance of the team involved in the process as a whole, with the scores obtained being similar to other studies with a greater number 
of subjects.

The assessment of the independent life skills of the users showed that the scores presented in the Employment domain were higher than those of other studies, although they were the lowest found in this study. This fact can demonstrate an improvement from the perspective of social reintegration, as well as the collaboration of mental health policy strategies regarding this aspect.

When the relationship between the burden and independence for daily living was analyzed, we identified domains with statistically significant correlations, all inversely related. This analysis corroborates the hypothesis that the reduced possibility of employment causes a moderate correlation with the subjective burden related to dealing with the problematic behavior of the patient. That is, the more the patient is able to perform some work activity, the less the family member feels burdened, since the problematic behavior of the patient will be more attenuated.
The results indicate that the implementation of the Psychosocial Care Center in the city under study has contributed to the psychosocial rehabilitation of users with mental disorder, as both family members and patients presented acceptable satisfaction scores, although with different perceptions regarding the improvement of the alterations caused by the mental disorder. This fact indicates the importance of investing in the reinsertion of these patients into the labor market, with it being necessary to articulate mental health services with other aspects of civil society, such as the social and labor spheres.

The main aspects identified in the study are relevant for professionals working in mental health services, such as psychiatrists, nurses and psychologists, since they contribute to the advancement of scientific knowledge, enabling better targeting of interventions with patients and their family members.

\section{CONFLicts OF INTEREST Disclosure}

The authors declare that there is no conflict of interest.

\section{REFERENCES}

[1] Tannenbaum C, Lexchin J, Tamblyn R, et al. Indicators for measuring mental health: towards better surveillance. Health Policy. 2009; 5(2): e177-186. https://doi.org/10.12927/hcpol.2013.21180

[2] Kisely S, Adair CE, Lin E, et al. Routine outcome measures in Canada. Int Rev Psychiatry. 2015; 27(4): 286-95. PMid:25738745 https://doi.org/10.3109/09540261.2014.994594

[3] Han H, Ahn DH, Song J, et al. Development of mental health indicators in Korea. Psychiatry Investig. 2012; 9(4): 311-8. PMid:23251193 https://doi.org/10.4306/pi.2012.9.4.311

[4] Baars IJ, Evers SM, Arntz A, et al. Performance in mental health care: present situation and future possibilities. Int J Health Plann Manage. 2010; 25(3): 198-214. PMid:19213020 https://doi .or $\mathrm{g} / 10.1002 / \mathrm{hpm} .951$

[5] Amorim MF, Otani MAP. Psychosocial rehabilitation in Psychosocial Care Centers: an integrative review. SMAD - Rev Eletr Saúde Ment Álc Drgs. 2015; 11(3): 168-177. https ://doi.org/10.11606/i ssn. 1806-6976.v11i3p168-177

[6] Andrade JMO de, Silva PMC, Azevedo EB de, et al. Services users families conceptions of the offered in a psychosocial care center. Cogitare Enferm. 2013; 18(1): 156-62.

[7] Assunção AA, Lima EP, Guimarães MDC. Mental disorders and participation in the labor market: a multicenter national study in Brazil. Cad. Saúde Pública. 2017; 33(3): e00166815. PMid:28380147 https://doi.org/10.1590/0102-311x00166815

[8] Keszei AP, Noval M, Streiner DL. Introduction to health measurement scales. J Psychos Res. 2010; 68(4): 319-23. PMid:20307697 https://doi.org/10.1016/j.jpsychores.2010.01.006

[9] Camatta MW, Nasi Cíntia, Nickel AA, et al. Evaluation of a psychosocial care center: the view of the Family. Ciênc. saúde coletiva [Internet]. 2011 Nov; 16(11): 4405-4414. https : //doi .org/10.1 590/S1413-81232011001200013
[10] Camilo C, Aparecida BM, Leal de RMAC, et al. Avaliação da satisfação e sobrecarga em um serviço de saúde mental. Cad. Saúde Col. 2012; 20(1): 82-92.

[11] Champagne F, Astrid B, Hartz Z, et al. A Avaliação no Campo da Saúde: conceitos e métodos.p.41-60. In: F. Champagne, A. Brouselle. Z. Hartz, A. Contandriopoulos (Orgs). Avaliação: conceitos e métodos (pp.41-60). Rio de Janeiro, RJ: Fiocruz. 2011.

[12] Alves PF, Kantorski LP, Coimbra CC, et al. Qualitative indicators of satisfaction in mental health. Saude Debate. 2017; 41(n.esp): 50-9. https://doi.org/10.1590/0103-11042017s05

[13] Onocko-Campos R, et al. Evaluation Indicators for the Psychosocial Care Centers Type III: results of a participatory. Saude Debate. 2017; 41(n.esp.): 71-83. https ://doi.org/10.1590/0103-110 42017 s 07

[14] Kantorski LP, Jardim VR, Wetzel C, et al. User satisfaction with psychosocial healthcare services, Southern Brazil. Rev. Saúde Pública. 2009; 43(Suppl 1): 29-35. PMid:19669062 https ://doi .org/10 .1590/S0034-89102009000800006

[15] Costa CS, Bandeira M, Cavalcanti RLA, et al. Perceptions by patients and families towards treatment outcomes in mental health services. Cad. Saúde Pública. 2011; 27(5): 995-1007. PMid:21655850 https://doi.org/10.1590/S0102-311X2011000500017

[16] Martini LC, Attux CBRA, Mari J de J. Cultural adaptation, reliability and validity of the Brazilian version Independent Living Skills Survey (ILSS-BR/P) with schizophrenic patients for schizophrenia. Rev. Psiquiatr. Clín. 2012; 39(1): 12-18. https ://doi.org/10.1 590/S0101-60832012000100003

[17] Bandeira M, Calzavara MGP, Costa CS, et al. Mental health services evaluation: transcultural adaptation of a user's reported outcome measure. J. Bras. Psiquiatr. 2009; 58(2): 107-114. https : //doi.org/10.1590/S0047-20852009000200007 
[18] IBGE-Instituto Brasileiro de Geografia e estatística. PAS - Pesquisa Anual de Serviços. 2014.

[19] Bandeira M, Silva MA da. Patients' Satisfaction with Mental Health Services Scale (SATIS-BR): validation study. J Bras Psiquiatr. 2012; 61(3): 124-132. https://doi.org/10.1590/S0047-2085201 2000300002

[20] Bandeira M de B, Andrade MCR, Costa CS, et al. Patient's perception on the treatment in mental Health services: validating the Perception of Change Scale - patient version. Psicologia: Reflexão e Crítica 2011; 24(2): 236-244. https://doi.org/10.1590/S0102-797 22011000200004

[21] Bandeira M, Lima LA, Gonçalves S. Independent Living Skills Survey of Psychiatric Patients (ILSS-BR). Rev Psiq Clín. 2003; 30(4): 121-5. https://doi.org/10.1590/S0101-608320030 00400002

[22] Bandeira M, Calzavara MGP, Varella AAB. Family burden scale for caregivers of psychiatric patients: transcultural adaptation to Brazil (FBIS-BR). J Bras Psiquiatr. 2005; 54(3): 206-214.

[23] Batista CF, Bandeira M, Oliveira DR. Factors associated with the overburden of male and female caregivers of psychiatric patients. Ciênc. Saúde Coletiva. 2015; 20(9): 2857-2866. PMid:26331517 https://doi.org/10.1590/1413-81232015209.03522014

[24] Thiengo DL, Fonseca D, Abelha L, et al. Family satisfaction with a Children and Youth Psychosocial Care Center service (CAPSi) in the city of Rio de Janeiro. Cad. Saúde Col. 2015; 23(3): 298-308. https://doi.org/10.1590/1414-462X201500030172

[25] Resende KIDS, Bandeira M, Oliveira DCR. Assessment of Patient, Family and Staff Satisfaction in a Mental Health Service. Paidéia. 2016; 26(64): 245-253. https://doi.org/10.1590/1982-432 72664201612
[26] Miranda PO de, Souza OF de, Ferreira de FT. Evaluation of satisfaction of patients and relatives in a mental health service in the city of Rio Branco, Acre. J. Bras. Psiquiatr. 2014; 63(4): 332-340. https://doi.org/10.1590/0047-2085000000042

[27] Pinho LB, Kantorski LP, Wetzel CSE, et al. Therapeutic activities: comprehension of families and profesionals at a mental health service. Esc. Anna Nery. 2013; 17(3): 534-541. https://doi.org/10.1 590/S1414-81452013000300018

[28] Wagner LC, Fleck MP, Almeida WM, et al. Autonomy of longstay psychiatric inpatients. Rev. Saúde Pública. 2006; 40(4): 699705. PMid:17063248 https://doi.org/10.1590/S0034-891 02006000500021

[29] Silva MA da, Bandeira M, Scalon JD, et al. Patients' satisfaction with mental health services: the perception of changes as predictor. $\mathrm{J}$ Bras Psiquiatr. 2012; 61(2): 64-71. https://doi.org/10.1590/ S0047-20852012000200002

[30] Vidal CEL Leal GECDM, Bandeira MB. Evaluation of independent living skills and social behavior of patients discharged from psychiatric hospitals. Rev. Psiquiatr. Rio Gd. Sul. 2007; 29(3): 294-304. https://doi.org/10.1590/S0101-81082007000300009

[31] Santos ZD dos, Munhoz TN. Users' perceptions of change after treatment at a Psychosocial Care Center. Rev Bras Pesq Saúd. 2015; 17(2): 22-27.

[32] Reis TL dos, Dahl CM, Barbosa SM, et al. Burden and participation of family in the care of Psychosocial Care Centers users. Saúde Debate. 2016; 40(109): 70-85. https : //doi .org/10.1590/0103-1 104201610906

[33] Barroso SM, Bandeira M, Nascimento E do. Burden in family caregivers of psychiatric patients attending public services. Rev. Psiquiatr. Clín. 2007; 34(6): 270-277. https://doi.org/10.1590/S010 $1-60832007000600003$ 